\title{
Aporías de la investigación en arquitectura: adaptación del modelo científico en la producción y divulgación del conocimiento explícito
}

\author{
Joaquín Llorca ${ }^{1}$
}

Recibido: 12-07-2020 | en su versión final: 24-01-2021

Resumen

\begin{abstract}
La múltiple condición disciplinar de la arquitectura involucra una diversidad de saberes muchos de los cuales se adquieren y difunden desde la práctica, es decir, de forma tácita. Sin embargo, la arquitectura también está conformada por un conocimiento explícito que se puede conservar y transmitir con claridad y del cual se ocupa este texto. Las exigencias académicas actuales han afianzado un modelo de investigación científica no habitual para la arquitectura que en el siglo XX había consolidado su producción teórica por medio de revistas y libros independientes no arbitrados. El nuevo modelo ha propiciado debates sobre la pertinencia y posibilidad de adaptar disciplinas creativas a estándares de investigación y difusión científicos. Con el objetivo de poner tal problemática en perspectiva, este artículo examina las formas hegemónicas de producción y divulgación del conocimiento arquitectónico y aporta un panorama teórico sobre lo que significa investigar en arquitectura. Argumenta que la arquitectura, además de su componente técnico, tiene un papel sociocultural que se constituye en una forma de conocimiento a desarrollar por medio de la investigación científica y para evidenciarlo presenta un original análisis de teorías paradigmáticas del siglo XX (Le Corbusier y Robert Venturi con Denise Scott Brown) bajo los criterios de una producción de conocimiento metódico susceptible de divulgar en publicaciones científicas.
\end{abstract}

Palabras clave: Investigación-creación; revistas de arquitectura; artículos académicos; conocimiento tácito

Citación

Llorca, J. (2021). Aporías de la investigación en arquitectura: adaptación del modelo científico en la producción y divulgación del conocimiento explícito. ACE: Architecture, City and Environment, 16(46), 9531. DOI: http://dx.doi.org/10.5821/ace.16.46.9531

\section{Research Aporiae in Architecture: Adapting the Scientific Model to the Production and Dissemination of Explicit Knowledge}

Abstract

\begin{abstract}
The multi-disciplinary condition of architecture involves a diversity of knowledge. Much of this knowledge is tacit; it is acquired and disseminated from practice. However, this paper deals with the explicit architectural knowledge that can be clearly conserved and transmitted. In the 20th century, architecture had consolidated its theoretical production through independent magazines and books, without peer-review but current academic demands have strengthened an unusual scientific research model for architecture. The new model has sparked debates about the relevance and the possibility of adapting creative disciplines to scientific research and dissemination standards. This article examines the hegemonic forms of production and dissemination of architectural knowledge to put such problems in perspective. It provides a theoretical overview of what research means in architecture and argues that, in addition to its technical component, architecture has a socio-cultural role that constitutes a form of knowledge to be developed through scientific research. To demonstrate this, it presents an original analysis of paradigmatic theories of the 20th century (Le Corbusier and Robert Venturi with Denise Scott Brown) applying the criteria of a methodical production of knowledge liable to be published in scientific journals.
\end{abstract}

Keywords: Practice-based research; architecture journals; academic papers; tacit knowledge

${ }^{1}$ Arquitecto PhD, Facultad de Creación y Hábitat. Pontificia Universidad Javeriana, Cali, Colombia (ORCiD: 0000-0003-4580-6545, Scopus Author ID: 55795050500, WoS ResearcherID: AAR-4301-2021) Correo de contacto: joaquin.llorca@javerianacali.edu.co

ACE, 16 (4.6) CC BY-ND 3.0 ES | UPC Barcelona, España | Aporías de la investigación en arquitectura: adaptación del modelo científico en la producción y divulgación del conocimiento explícito. DOI http://dx.doi.org/10.5821/ace.16.46.9531 


\section{Introducción: entre la ciencia y el arte}

En el presente artículo se entiende investigación como un trabajo sistemático que implica la recopilación, organización y análisis de información con el fin de producir nuevo conocimiento susceptible de ser difundido de manera explícita. En la arquitectura, siglos antes de formalizarse en las academias de Occidente, la transmisión del conocimiento se desarrollaba de forma tácita, desde la práctica. Aún hoy se sigue un modelo similar de maestro-aprendiz en el que se prioriza la adquisición inconsciente de conocimientos. Sin embargo, la arquitectura también comporta un saber estructurado, que se puede conservar y transmitir con claridad de un individuo a otro, es decir, el conocimiento explícito; que se construye a través de una indagación y síntesis sistemática cuyo objetivo es su comunicación por medio de documentos.

Con una tradición académica consolidada en más de dos siglos, la investigación en la arquitectura ha sido un campo difuso alimentado por un debate que se fundamenta en la naturaleza misma de una disciplina validada desde la práctica. Este campo difuso se refuerza por la convergencia de saberes técnicos y estéticos en el aprendizaje y la práctica arquitectónica. Los edificios, su objeto de estudio principal, son complejos sistemas con alcances sociales y ambientales que se insertan en la cultura y que además hacen parte de otro sistema más complejo aún: la ciudad, lo cual involucra la confluencia de conocimientos plurales, amplios y articulados.

La ciencia ha configurado por siglos un contexto y unos protocolos comunes sobre los cuales construir una colectividad científica amplia que puede compartir ideas y estimular la resolución de problemas. Apuntalada en estos métodos, la práctica académica de las ciencias sociales y de las humanidades, consolidó estrategias dirigidas a una producción de conocimiento racional y metódico. De otro lado, el artista, volcado totalmente hacia la creación, hacia la poiesis, nunca necesitó producir más que sus obras. El aprendizaje, y cualquier reflexión al respecto, apuntaba hacia lo aplicado, hacia el "cómo hacer", es decir, la tekné.

Durante el siglo XVIII, la burguesía emprende una sistematización y codificación del conocimiento occidental cuyo símbolo e instrumento es la Encyclopédie. Quedaron definidas dos esferas de aproximación al conocimiento: por un lado, la naturaleza y por el otro la cultura'. En la arquitectura, que contiene ambas, el componente material ha quedado cubierto por una investigación aplicada y empírica dirigida a la práctica que encaja en los métodos de la ingeniería y se preocupa por aspectos de la física como la materialidad, las fuerzas estructurales o sus interacciones ambientales mensurables. Pero el conocimiento restante, del que trata este texto, es el que considera la arquitectura como un campo que debe ocuparse de la producción humana del espacio, del papel del edificio en la sociedad y del contexto histórico en el que vivimos; se fue acomodando entre las humanidades, las ciencias sociales y las artes. Estas últimas, dedicadas a la creación, se fundaban sobre un conocimiento tácito y no habían desarrollado reflexiones sobre sí mismas, (episteme). Desde subcampos propios, la filosofía, la historia y posteriormente la sociología, eran las encargadas de pensar la creación y sus productos, además de difundir aquel conocimiento de forma explícita. Tal forma de conocimiento se cimentó en procesos interpretativos de indagación basados en diversas formas metodológicas que Creswell y Poth (2018) definen en cinco grupos: la etnografía, la fenomenología, la teoría fundamentada en los datos, la biografía y el estudio de casos. Con independencia de los métodos, no hay una sola forma de investigar el mundo desde lo cualitativo. Existen diversas aproximaciones a la realidad que expresan los límites de lo que puede ser conocido y que enriquecen la construcción de imágenes complejas sobre ella.

\footnotetext{
${ }_{1}^{1}$ Para una aproximación histórica al establecimiento de los modelos epistemológicos ver Ginzgurg, 1999.
}

ACE, 16 (4.6) CC BY-ND 3.0 ES | UPC Barcelona, España | Aporías de la investigación en arquitectura: adaptación del

modelo científico en la producción y divulgación del conocimiento explícito. DOI: http://dx.doi.org/10.5821/ace.16.46.9531 
En el siglo XX la institución educativa occidental, con su componente investigativo, se fortaleció de manera progresiva apoyada en una cientificidad que condujo a los diferentes campos hacia reflexiones pedagógicas, disciplinares y a la formalización de su producción de conocimiento. La arquitectura, considerada por algunos sectores como una actividad práctica, un oficio y una técnica que no depende de consideraciones teóricas diferentes a las del quehacer, se vio abocada a este proceso.

Una revisión histórica muestra que la gran mayoría del conocimiento arquitectónico, diferente al aplicado, surgió de la teoría y la crítica más que de la investigación formal. Dado que la crítica implica un juicio estético, muchos de los análisis sobre edificios acuden a valoraciones nacidas de sensibilidades subjetivas que mezclan análisis y síntesis desde el acervo cultural, ideología y gusto de quien escribe. La crítica se apoya en teorías, es decir, interpretaciones de la producción a la luz de las formas del conocimiento del momento. Por otra parte, como la producción edilicia comporta tantos frentes, es recurrente que sus interpretaciones utilicen los enfoques y lenguajes del arte, la ciencia y el mundo de las ideas, en cabeza de la filosofía y la historia.

Ante la realidad actual de un paradigma científico generalizado en el mundo académico al que la investigación en la arquitectura se ve expuesta, surgen las siguientes preguntas ¿Tiene la arquitectura una naturaleza epistemológica diferente que implica modos aislados y únicos de producir conocimiento? ¿Qué posibilidad hay de confrontar la reflexión arquitectónica producida bajo la política editorial de siglo XX con el modo actual de divulgación académica? ¿Es posible pensar y divulgar dichas teorías desde un modelo científico?

Al hilo de lo anterior, este artículo examina la evolución de las formas hegemónicas de producción y divulgación del conocimiento arquitectónico e incorpora un panorama teórico destinado a pensar lo que significa investigar en la arquitectura. Analiza puntualmente dos casos paradigmáticos de la producción teórica del siglo XX (Le Corbusier y Robert Venturi con Denise Scott Brown) a la luz de métodos científicos y declara que el conocimiento arquitectónico es susceptible de presentarse en marcos establecidos por dicha tradición. A pesar de mirar al pasado, no es un texto revisionista que pretenda hacer crítica de las teorías, sino que busca pensar el presente apoyado en evidencias históricas y teóricas sobre los modos de producción de conocimiento.

Además de la realización de proyectos o edificios existe un espacio para pensar la arquitectura en el cual muchos profesionales están incursionando gracias a la proliferación de estudios de postgrado en los que la investigación permite abordar cualquier faceta de la arquitectura independientemente de valoraciones disciplinares. El artículo pretende contribuir al creciente y nuevo campo que plantea debates enriquecedores sobre la naturaleza disciplinar de la arquitectura gracias a su condición teórico-práctica.

\subsection{Los medios y la forma: del magazine al journal}

Muchos siglos atrás la arquitectura comenzó su producción teórica documentada con enfoques ontológicos, estéticos y técnicos indistintamente. Los tratados antiguos (Vitrubio, siglo I a. C. y en el Renacimiento Filarete, siglo XV; Alberti, siglo XV; Palladio siglo XVI, etc.) enfatizaban el carácter del orden, entendido como la perfecta relación entre el todo y las partes. Posteriormente, la gran cantidad de tratados, nacidos entre el siglo XVIII y XIX bajo el influjo de la ilustración (Laugier, Blondel, Boullée, Semper, le-Duc, etc.), buscaban la esencia, una verdad universal profunda encarnada en la arquitectura y desvelada por la razón. Bajo esta influencia en el siglo XX las teorías oscilaron entre el racionalismo proyectual y la fenomenología, hasta la llegada del estructuralismo y la semiología en los años sesenta cuando las indagaciones trataron sobre el significado. En este periodo se formalizó también la incorporación de lo cultural al discurso dominante a través de la mirada regional.

ACE, 16 (4.6) CC BY-ND 3.0 ES | UPC Barcelona, España | Aporías de la investigación en arquitectura: adaptación del

modelo científico en la producción y divulgación del conocimiento explícito. DOI: http://dx.doi.org/10.5821/ace.16.46.9531 
Finalizando el siglo, muchas teorías de la arquitectura se apoyaron en ideas filosóficas postestructuralistas, sin embargo, los textos más difundidos los han escrito arquitectos que se ocupan de validar su propia práctica desde la producción teórica.

El anterior panorama permite determinar dos características fundamentales de la producción teórica dominante desde el siglo XX: sus medios principales de difusión y las formas utilizadas para expresar y estructurar el conocimiento que compone su corpus. Por un lado, revistas y libros de reconocidas editoriales independientes y por el otro, ensayos de carácter crítico sin estructura definida y que no nacen necesariamente de hipótesis ni de procesos de indagación con una metodología previamente establecida.

Al margen de la validez o trascendencia de las ideas surgidas en torno a la tradición intelectual de la arquitectura, es una realidad que su efectividad comunicativa está ligada a la difusión mediática. Eso significa que, además de los contendidos, hay también un mensaje encarnado en los medios de difusión. Como apunta Colomina (2012), Le Corbusier no existía antes de vers une architecture, Urbanisme, L'art decoratif d'aujourd'hui, Almanach. El suizo se hizo conocido y creó una clientela gracias a su literatura. Colomina va más allá y establece que la arquitectura moderna se convirtió en "moderna" no por su uso del vidrio, acero u hormigón armado, sino por su interacción con los medios de comunicación: publicaciones, concursos, exposiciones. Es decir, no existe un relato sin un medio y la construcción de aquellas narrativas no estuvo a cargo de una comunidad científica consolidada, sino que se desarrolló en un escenario con variados actores como arquitectos, artistas, editores e historiadores.

Las revistas independientes de arquitectura (Architectural Record, 1891; Architectural Review, 1896; Architectural Digest, 1920; Domus, 1928; Casabella, 1928; L'Architecture d'Aujourd'hui, 1930, etc.), constituidas como grandes emporios editoriales, fueron el medio que casi monopolizaba e instituía, tendencias, lenguajes, figuras y proyectos relevantes en la arquitectura mundial. La consolidación del movimiento moderno coincidió con la de las grandes revistas. Este escenario liberal era básicamente un lugar para la crítica, no exento de influencias e intereses comerciales.

En ese contexto, como un contrapunto a la institución de las revistas dominantes, apareció Oppositions (1973-1984) publicada por el Institute for Architecture and Urban Studies. Con un fin plenamente teórico, que pretendía dar voz a todos los debates, la revista tuvo 26 números con contribuciones de Stanford Anderson, Alan Colquhoun, Peter Eisenman, Kenneth Frampton, Rem Koolhaas, Rafael Moneo, Aldo Rossi, Colin Rowe, Ignasi de Solà-Morales, Manfredo Tafuri, Bernard Tschumi y Anthony Vidler, entre otros. Oppositions se volvió un referente del fin de siglo y estableció puentes con la academia colaborando con MIT Press para divulgar el pensamiento arquitectónico de, quizá, la última élite que buscaba nuevas rutas teóricas dentro del mismo modelo tradicional centralizado.

Siguiendo a Torrent (2013), las revistas tuvieron un papel importante, pues fueron agentes dinamizadores de la disciplina y un recurso clave para entender el pensamiento de la cultura arquitectónica que ayudó a construir la historiografía de la modernidad. Fueron además proyectos, con la pretensión de intervenir en la historia para transformar el pensamiento y práctica de la arquitectura y el urbanismo. "Cristalizaron en su publicación las elecciones éticas, estéticas e ideológicas, las formas en que sus editores o directores recortaron el mundo, así como las intenciones de transformación de las sensibilidades de sus posibles lectores” (Torrent, 2013, pág. 7).

El aparato editorial tendría un poder inmenso en la narrativa oficial de la arquitectura moderna. El austríaco Richard Neutra, gracias a los medios impresos, consiguió con rapidez gran notoriedad y pasó a "convertirse en el principal y mayor representante del funcionalismo tecnológico, además de

ACE, 16 (4.6) CC BY-ND 3.0 ES | UPC Barcelona, España | Aporías de la investigación en arquitectura: adaptación del

modelo científico en la producción y divulgación del conocimiento explícito. DOI: http://dx.doi.org/10.5821/ace.16.46.9531 
estandarte americano y figura de absoluta referencia dentro del panorama de la arquitectura moderna a nivel internacional" (Alcolea, 2012, pág. 23). Neutra escribió en Estados Unidos su exitoso libro Wie Baut Amerika? (1927) un manifiesto a favor de la arquitectura norteamericana. De hecho, "el texto mezcla las descripciones de proyectos construidos con sus propios planteamientos teóricos, por lo que es posible intuir la idea de fondo de impedir el discernimiento entre la realidad y sus propuestas teóricas" (Alcolea 2012, pág. 24). El éxito del libro, y la proyección de Neutra, están ligados a la elogiosa reseña que el historiador Henry-Russell Hitchcock hizo en Architectural Record de junio de 1928.

Este ámbito de divulgación contrasta con el tejido académico contemporáneo que discurre bajo otras condiciones en las que el ensayo o la descripción de proyectos no responden a las exigencias de un método sistematizado y contrastado que la academia exige y pondera. Un ejemplo que revela el procedimiento habitual de las publicaciones tradicionales de arquitectura es el análisis que Gastón y Rovira (2007) hacen de la obra de Werner Blaser, un reconocido autor que cuenta con docenas de publicaciones y más de diez títulos sobre Mies Van der Rohe. Su punto de vista está determinado por su formación como arquitecto y fotógrafo, y por la cercanía con el mismo Van der Rohe. En referencia al libro Mies van der Rohe. The Art of Structure de 1965, Gastón y Rovira (2007) apuntan: "Blaser no es un investigador erudito, a diferencia de otros [...]. En sus libros, no cabe buscar citas o referencias bibliográficas; carece de la precisión de historiador o de profesor de universidad [...]". Señalan además errores como "intercalar la reproducción de dibujos originales con dibujos realizados por él sin indicarlo expresamente” (Gastón y Rovira, 2007, pág. 50). A lo anterior se puede añadir que la motivación del autor por publicar no está regida sólo por un interés intelectual. "De hecho, la estructura del libro parece responder al interés de Mies en reeditar un proyecto editorial propio de 1944 con la editorial Paul Theobald con el título Architecture: Estructure and Expression, proyecto no realizado" (Gastón y Rovira, 2007, pág. 50).

Por múltiples razones, esta línea editorial comenzó a perder su liderazgo, como declara Otxotorena (2012): "Hace ya tiempo que las revistas han dejado de tener el carácter que tuvieron de escaparate de lo ideal y lo deseable, de lo debido y aun de lo utópico, ligado al horizonte de una nueva sociedad". Su presente tiene poco que ver con la agitación del proyecto moderno. "Las vemos ya, a veces, tan ayunas de contenido conceptual como abonadas a la seducción del couché: repletas de espectáculo y novedades en materia formal. Son los signos de los tiempos, y sin duda hay que fijarse en ellos" (Otxotorena, 2012, pág. 9).

La contraparte académica de esta práctica editorial se posiciona como una alternativa en la que, teóricamente, cualquiera que cumpla con el rigor necesario tiene la posibilidad de publicar. Poco a poco, las revistas arbitradas de arquitectura se consolidan como medio habitual de los académicos y en esta vertiente, muy diferente al modelo del arquitecto que difunde o interpreta (sus) obras, aparece el profesional que responde a otros métodos e intereses que propician y dan valor a la reflexión sobre el significado de investigar en arquitectura. Del magazín se pasa al journal y publicaciones especializadas que ocupan los mejores puestos en los rankings académicos (International Journal of Architectural Heritage, Spatium, The Journal of Architecture, Design Studies; Architecture, City and Environment; Urbe, Revista INVI, Journal of Architecture and Urbanism, Frontiers of Architectural Research, etc.), nacidas en las universidades o en grandes editoriales académicas (Routledge, Taylor \& Francis Group, Sage Publishing, Elsevier), se establecen como el espacio de difusión de los hallazgos surgidos bajo métodos científicos. Estas editoriales también tienen un gran poder ya que representan el nivel de reconocimiento de la comunidad científica y otorgan a los autores el puntaje que avala la calidad de los grupos de investigación y las universidades a las que pertenecen los académicos.

ACE, 16 (4.6) CC BY-ND 3.0 ES | UPC Barcelona, España | Aporías de la investigación en arquitectura: adaptación del

modelo científico en la producción y divulgación del conocimiento explícito. DOI http://dx.doi.org/10.5821/ace.16.46.9531 
A pesar de su apertura, el modelo no está exento de críticas. La valoración de las revistas se basa en la bibliometría, es decir, la visibilidad mundial por la presencia en consultas digitales o bases de indexación (Scopus, Publindex, Google Scholar, etc.). Los rankings están dominados por Estados Unidos e Inglaterra quienes gestionan los factores de medición y tienen editoriales académicas tan poderosas como cualquier otra empresa. En el Scimago Journal and Country Rank, de las primeras 20 revistas bajo la categoría "Arquitectura”, tan solo hay 5 que no son de esos dos países. La situación pone en desventaja a las revistas en otras lenguas que, además de la barrera idiomática, tienen la presión de visibilizarse internacionalmente ante la importancia de los índices de citación en el ranking de la investigación y la clasificación de las universidades.

En otras palabras, se comenzó a configurar el tránsito de un modelo de acceso bastante cerrado y de producción limitada con una valoración social en la que el impacto estaba presidido por una exclusiva élite disciplinar y editorial; a un modelo abierto a la comunidad académica con evaluación cuantitativa regida por la comunidad científica con parámetros de medición teóricamente homogéneos. Tal conformación alimenta un debate sobre la inconveniente adaptación del conocimiento surgido de disciplinas creativas a modelos epistemológicos nacidos de la física. Sin embargo, cómo se irá exponiendo, el pensamiento crítico estructurado tiene cabida en cualquier campo, incluso el creativo.

\section{Antecedentes de la investigación en campos creativos}

Si antes la voz del pensamiento arquitectónico se desarrollaba desde la relación crítica-práctica, la balanza se fue inclinando hacia un entorno académico en el que las universidades tenían una voz que la arquitectura no había entonado tanto como otras carreras.

El cambio estructural que impulsó la arquitectura a un nuevo escenario académico comienza en el Reino Unido, Australia y el norte de Europa en donde posteriormente se expande y consolida con el llamado Proceso de Bolonia, una reforma universitaria que arranca en 1998 y parte de una agenda de modernización en la educación, la investigación y la innovación. La reforma definió que, dentro de ciertos estándares académicos, las instituciones de educación superior europeas estarán acreditados para impartir títulos de licenciatura, maestría y doctorado. En ese contexto, la educación artística superior se comprometió a implementar el Proceso de Bolonia.

El origen del debate sobre la investigación artística se remonta a la década del setenta en el Reino Unido cuando se plantearon preguntas sobre el estado de los programas de arte en la educación superior y su papel en prácticas institucionales como la investigación en relación a la tradicional estructura de maestrías y doctorados. Como mecanismo de integración, apareció el concepto investigación-creación (Practice-based research ó practice-led research), que se sustenta sobre la limitación de las ciencias para abordar completamente la complejidad del conocimiento humano en toda su riqueza artística, por tanto, los investigadores buscaron ampliar el panorama metodológico abierto por los investigadores cualitativos (Sullivan, 2006).

Esta postura defiende que en la investigación-creación las artes proporcionan una forma especial de llegar a comprender algo. A medida que los métodos se amplían dentro del dominio de la investigación cualitativa en las ciencias sociales, existe la necesidad de poder incorporar las artes como formas que representen más adecuadamente la amplitud del conocimiento humano (Sullivan, 2006). Pero la práctica científica investigativa, basada en el positivismo, tiene una condición básica: la evidencia. Bajo ese estándar, fines tan complejos como el acto creativo, o la imaginación, tienen problemas para evidenciarse. Según Sullivan (2006), la sacudida al estatus académico sufrido por carreras creativas generó crisis de identidad, celos y choques de confianza cuando se replantearon

ACE, 16 (4.6) CC BY-ND 3.0 ES | UPC Barcelona, España | Aporías de la investigación en arquitectura: adaptación del

modelo científico en la producción y divulgación del conocimiento explícito. DOI: http://dx.doi.org/10.5821/ace.16.46.9531 
las estructuras y, en algunos casos, se cedió el control a otras disciplinas con mayor tradición científica (Sullivan, 2006). En este escenario, la arquitectura, con su dimensión creativa, quedó en medio. De forma similar al arte, su producción proviene de una indagación y se objetiva en una creación, pero, al igual que el arte, no se había acoplado mucho con procesos académicos globales, era independiente y autorregulada. En ese contexto, productos editoriales universitarios con reflexiones surgidas de la subjetividad sin convenio con nada externo, quedaban fuera del sistema de puntajes de las revistas científicas ajustadas a rigurosos estándares internacionales.

El nuevo modelo exige entonces que la producción dentro del ámbito académico debe cumplir con ciertos parámetros de calidad: la investigación debe ser creíble y auténtica; debe contribuir al conocimiento aportando una mayor comprensión de lo que ya se conoce; debe ser clara en diseño y divulgación por medio de enfoques cuidadosos y sistemáticos; debe igualar criterios legales y éticos y debe usar criterios dependientes de paradigmas (Furlong y Oancea, 2005).

Volviendo a la arquitectura, el debate sobre investigar fue alimentando un malentendido basado en el proceso de diseño, puesto que para realizar un edificio hace falta recabar una información de manera organizada que lleve a la formulación de la idea en términos objetuales, es decir, la recolección y organización de información conducente a su concreción. Este proceso de diagnóstico, suele ser considerado como un trabajo de investigación per se, lo que deriva en la creencia generalizada de que proyectar un edificio es un instrumento de investigación, una herramienta para la producción de conocimientos. En su informe para la RIBA Jeremy Till (2007) define estas creencias como "mitos" a derribar argumentando que el proceso de diseño no basa sus decisiones a través de evaluaciones sistemáticas y que el conocimiento creado en un edificio no es explícito ni comunicable, condiciones básicas de los resultados de cualquier investigación². En consecuencia, el término investigación-creación implica mucho más que diseñar un edificio o realizar una pintura. Se trata de un tipo de investigación en la que las prácticas profesionales y/o creativas del arte, el diseño o la arquitectura desempeñan un papel fundamental. Sin embargo, esto no quiere decir que la práctica sea un método de investigación. La práctica es una actividad que puede emplearse en la investigación, pero el método siempre debe incluir una comprensión explícita de cómo la práctica contribuye a la investigación y cómo la investigación se distingue de otras formas de práctica por esa comprensión explícita (Rust, Mottram y Till, 2007).

\subsection{El caso de la arquitectura}

Si bien el liderazgo en la formalización de la investigación universitaria ha sido ejercido por países europeos y anglosajones, en la actualidad hay una tendencia mundial a ajustarse a estándares comunes dada la necesaria homologación internacional de títulos de doctorado que redunda en movilidad, globalización e intercambio dentro de un lenguaje común. Los procesos de ajuste han suscitado en el entorno académico de la arquitectura interrogantes que desde la coyuntura actual buscan revisar la pertinencia de las estructuras ya establecidas desde el siglo XX. En la década del setenta Hillier y Leaman (1976) ponían sobre la mesa el debate actual y se preguntaban si el estudio del entorno construido era un tema en sí mismo o simplemente un lugar de encuentro para una serie de disciplinas. Concluían que existe la posibilidad de una investigación orientada hacia la comprensión de los códigos sociales que construyen la conciencia del espacio y nuestras acciones como diseñadores. Así mismo auguraban que la arquitectura podía convertirse en parte de la comunidad de ciencias modernas sin sacrificar nada de su preocupación por lo humano, lo intuitivo y por el libre funcionamiento de la imaginación socioespacial. Se trata de una mirada integradora que invitaba a la arquitectura a ponerse al día en una investigación metódica sin renunciar a su esencia.

\footnotetext{
2 Para un análisis de cómo se generan y organizan los conocimientos de la arquitectura con fines proyectuales ver Fayos
} (2017). El autor realiza un análisis de las fases del proyecto a la luz del paradigma indicial de Ginzburg.

ACE, 16 (4.6) CC BY-ND 3.0 ES | UPC Barcelona, España | Aporías de la investigación en arquitectura: adaptación del

modelo científico en la producción y divulgación del conocimiento explícito. DOI:

http://dx.doi.org/10.5821/ace.16.46.9531 
Varios autores (Williams Robinson, 2001; Anderson, 2001; Wortham, 2007; Till, 2007) coinciden en que la "tensión" en asimilar modelos de indagación formales tiene que ver con el modo como se fue configurando la profesión y con la pluralidad de conocimientos que complejizan la definición de un campo disciplinar sin la claridad que lo hacen otras carreras. Para Julia Williams Robinson (2001) la relación entre arquitectura e investigación pasa por desarrollar, primero, una completa revisión crítica a una disciplina que surgió a través de procesos históricos inconscientes y que debe ser objeto de una evaluación y reconstrucción crítica. Argumenta que existe una indefinición en su identidad y prueba de ello es que los departamentos de arquitectura están ubicados en entornos institucionales discordantes (institutos de tecnología, escuelas de arte, escuelas profesionales, colegios de artes liberales y, dentro de las universidades, en unidades tan diversas como artes liberales, artes y ciencias y diseño), lo que demuestra la falta de claridad sobre la naturaleza esencial del campo de conocimiento. Aun así, el conocimiento sobre la arquitectura, es decir, la teoría desarrollada en las academias ha comenzado a mostrar transformaciones al abandonar su proceder habitual y avanzar hacia un análisis crítico con resultados derivados, en parte, del modelo científico (Williams Robinson, 2001). Williams Robinson coincide con Sullivan (2006) en que la disciplina parece haberse fracturado por los conocimientos cada vez más diversos prestados de la ingeniería, el arte, la historia y las ciencias sociales. Sin embargo, establece una diferencia positiva en este carácter múltiple ya que el papel de la arquitectura es hacer síntesis de saberes muy diferentes. Sobre la educación resalta que la enseñanza habitual ha priorizado la adquisición inconsciente de conocimientos tácitos sobre la adquisición consciente de conocimientos explícitos debido a un modelo en que los estudiantes aprenden de la observación. El profesor tradicional, poseedor del conocimiento arquitectónico, enseña principalmente con el ejemplo y ejerce una especie de coaching (Williams Robinson, 2001). Tal sistema educativo supone que de algún modo (no especificado) el estudiante sintetizará los conocimientos explícitos, teóricos e históricos, en su aprendizaje tácito.

Ante esta estructura consolidada y monolítica, Williams Robinson (2001) enfatiza que hoy en día es insuficiente tener un modelo educativo que se dedique simplemente a afirmar experiencia. La experiencia debe estar respaldada por un cuerpo coherente de conocimiento definido con claridad y descrito verbalmente, es decir, el conocimiento explícito. Al carecer de esta competencia, la arquitectura se ha encontrado en desventaja en relación con otros campos y con un estatus cuestionable como profesión, lo que ha llevado al desarrollo de una investigación única y manifiestamente arquitectónica, en otras palabras, investigación sobre edificios, concebida por arquitectos y que solo habla a arquitectos. Este esquema educativo no incorpora fácilmente las formas de conocimiento explícito en su núcleo fundamental lo cual redunda en reflexiones informales sobre procesos y en discursos descriptivos sobre el modo de hacer arquitectura, con énfasis en la forma (Williams Robinson, 2001).

Existe entonces un reproche sobre aspectos que la arquitectura no ha asumido ni en su praxis ni en su crítica. Para Samuel (2017) es extraño que los arquitectos estén ausentes del creciente debate sobre los laboratorios de vida urbana para el cambio social y ambiental. De acuerdo a Gehl y Svarre (2013) la arquitectura se ha ocupado netamente del espacio y su forma, porque es fácil trabajar y comunicarse en ese plano; pero está ignorando la vida, las personas y la interacción de ellas con el espacio, lo cual es más difícil de describir por su carácter efímero (Gehl y Svarre, 2013). Es decir, asume una definición de espacio abstracta, reducida a lo euclidiano y que excluye, parafraseando a Lefebvre, la "producción del espacio" por la agencia humana. La tesis de Gehl y Svarre, puede explicar el por qué es más fértil el campo de investigación sobre teorías para proyectar (tekné) en las que prevalece el espacio y la forma en el sentido geométrico y tectónico.

El entendimiento de la arquitectura como forma y espacio es insuficiente para enmarcar el estudio del funcionamiento real del artefacto ambiental creado. Al mantenerse en su marco tradicional, las posibilidades de reflexión se reducen a los criterios internos de cómo se configura el edificio-objeto

ACE, 16 (4.6) CC BY-ND 3.0 ES | UPC Barcelona, España | Aporías de la investigación en arquitectura: adaptación del 8 modelo científico en la producción y divulgación del conocimiento explícito. DOI http://dx.doi.org/10.5821/ace.16.46.9531 
y esto deja por fuera el grado en que el espacio y la forma sirven a fines sociales o políticos, pues no son temas "arquitectónicos" (Williams Robinson, 2001).

En conclusión, el arquitecto se interesa por definir funciones, desde el entendimiento de un humano abstracto, pero no considera tanto el uso y además reprocha el "mal uso" que de sus obras se hace. Aunque es obvio que en el ejercicio profesional se trabaja desde un supuesto, que es la función y que la capacidad para intervenir en el uso real es incierta, la investigación sí tiene posibilidad de aportar conocimiento en ese plano, ya que puede indagar en la vida de las obras, sus consecuencias después del proyecto y las formas de interacción humana, para establecer diálogos entre la práctica y la teoría, habida cuenta del papel tan contundente que tiene la intervención en el hábitat. La investigación puede plantear interrogantes sobre causas, con el fin de encontrar el sentido y la finalidad de lo hecho. ¿Cómo situarse entonces ante el acto investigativo?

\subsection{El objeto de estudio y los diversos enfoques}

La definición específica de lo que significa investigar en arquitectura propicia diferentes perspectivas, algunas complementarias. En su informe para la RIBA, Till (2007) caracteriza las formas de investigar retomando a Fryling (1993-94) quien clasifica la investigación en arte y diseño desde una tríada: "en", "para” y "a través". Según el modelo de Fryling, "en”, supone la arquitectura como objeto de estudio; por ejemplo, investigaciones históricas o que evalúan el desempeño de edificios construidos desde diversas ópticas. La investigación "para" se refiere específicamente a aplicaciones futuras; incluido el desarrollo de nuevos materiales, tipologías y tecnologías. La investigación "a través" utiliza la producción y el diseño arquitectónico como parte de la metodología de investigación en sí. En esta clasificación la categoría inicial (en) se puede adecuar a la episteme, la segunda (para), a la tekné y la tercera (a través) a la poiesis. Del mismo modo, y aunque no sea una regla, la primera suele ser una investigación básica, la segunda aplicada y la tercera con posibilidades en ambos escenarios.

Por su naturaleza, y a diferencia de la música o la poesía, en arquitectura la poiesis tiene un carácter material, se realiza a través de la tekné y se manifiesta en la tektonikós. En ese proceso se configura un espacio para la investigación llamada "investigación proyectual". Siguiendo con el ejemplo de la música y la poesía, sería el equivalente a estudiar el contrapunto, la armonía o las figuras retóricas. La investigación sobre el proyecto explora aspectos del "cómo se hace o debe hacer" y se identifica con la exploración sobre la materialización del proceso de diseño. Busca instrumentalizar su conocimiento, es decir, es investigación aplicada y asume el hecho arquitectónico como un sistema autónomo e independiente que se resuelve por sus propias leyes internas con la limitación de que casi siempre deriva exclusivamente en los aspectos antes mencionados: forma y espacio.

Sobre la articulación entre teoría y práctica dentro del ejercicio profesional, Stanford Anderson (2001) destaca la condición de la arquitectura, entre la ciencia y el arte, con las ciencias sociales a medio camino. Esta circunstancia favorece el uso de diversas metodologías, según sea el enfoque, y propicia una distinción previa entre "disciplina" y "profesión" dado que en el ejercicio práctico hay ciertas formas de conocimiento excluidas. Le Corbusier, por ejemplo, hizo contribuciones a la profesión con su obra, pero también a la disciplina con postulados como los "cinco puntos de la arquitectura moderna" (Anderson, 2001, pág. 295).

Continuando con la pregunta central sobre la forma de encarar la investigación en la arquitectura, Wortham (2007, pág. 46) afirma que la producción de conocimiento depende de "lo transdisciplinar, de la identificación de patrones mayores y de la hermenéutica, tanto como de los hechos, las hipótesis y los resultados reproducibles. Esto significa mover la investigación especulativa e inventiva

ACE, 16 (4.6) CC BY-ND 3.0 ES | UPC Barcelona, España | Aporías de la investigación en arquitectura: adaptación del

modelo científico en la producción y divulgación del conocimiento explícito. DOI http://dx.doi.org/10.5821/ace.16.46.9531 
desde los márgenes al centro de lo que se considera un trabajo significativo". ${ }^{3}$ En este caso el énfasis está en ampliar lo disciplinar para que, partiendo de múltiples enfoques, se vaya construyendo el acercamiento a lo arquitectónico evitando lo autorreferencial.

Otros autores aluden a la investigación en arquitectura directamente desde las metodologías. Groat y Wang es su extenso Architectural Research Methods (2013) compendian y precisan siete categorías que llaman "estrategias": histórica, cualitativa, correlacional, experimental, investigación simulada, argumentación lógica y casos de estudio con estrategias combinadas. Dentro de esta misma tendencia se encuentran publicaciones que quieren servir de guía para el arquitecto investigador con definiciones epistemológicas y metodológicas de manera general sin pretender profundizar en el propio significado de investigar en arquitectura. Se limitan a describir los métodos de las ciencias sociales, como en Chávez (2015), o como en Lucas (2016), quien construye, a modo de manual, el marco del conocimiento y los procesos de investigación adaptándolos a casos de arquitectura.

Con una aproximación basada en la práctica (directed research embedded in practice), cabe mencionar el caso de Australia que ha creado un ecosistema en que el mundo académico y el profesional se pueden articular para producir conocimiento. Como explica Burry (2017), desde 2004 se estableció una modalidad que ha demostrado ser innovadora para la investigación y que se inspira en la medicina. La investigación en medicina tiene relación con la experiencia en el hospital, el espacio en el que se intersecan la indagación y la práctica médica y, como consecuencia directa, el aprendizaje clínico basado en problemas. El modelo parte de una premisa: es poco probable que las problemáticas de los profesionales lleguen a la academia y que la investigación clásica, que produce libros, documentos y ponencias, llegue a los profesionales del diseño. En Australia se implementan tres programas de doctorado, denominados: Práctica integrada, PhD por proyecto y PhD por publicación. Se dirigen hacia la investigación de diseño aplicado para jóvenes graduados y también para que arquitectos, con al menos 35 años de práctica, vuelvan a la universidad y examinen críticamente el trabajo de su carrera. Aunque Burry sitúa los programas dentro del conocimiento tácito, los resultados pueden entrar en el campo del conocimiento explícito y ampliar las posibilidades de investigación para los arquitectos dentro de un ámbito más disciplinar como lo es el diseño pero que puede también trascender a un conocimiento no necesariamente aplicado.

\subsection{Ars combinatoria o (in)disciplina}

El tema de la investigación arquitectónica deriva frecuentemente en una reflexión sobre la disciplina. Ateniéndose a conceptos sobre lo disciplinar es posible afirmar que la práctica de la arquitectura es por definición multidisciplinar, pues su objetivación necesita de varias disciplinas complementarias que le ayudan a cumplir su cometido. Debido a esto es también transdisciplinar, pues abarca varias disciplinas y las atraviesa para llegar a la síntesis final. Al mismo tiempo es interdisciplinar, porque partes de su conocimiento son tomadas de otros campos. ¿Cuál es entonces su esencia disciplinar si parece situarse en un campo de intersecciones?

El debate sobre lo disciplinar suele entrar en rutas sin salida y estériles. Philippe Boudon estima que la arquitectura simplemente no es por naturaleza una disciplina, sino que está conformada por varias, esto implica que no se defina por metodologías de investigación particulares, como sí sucede en muchos otros campos, sino por sus prácticas sintéticas (Williams Robinson, 2001). En consecuencia, la indefinición, o la indisciplina, más que un problema, es una fortaleza. Poseer la capacidad de intervenir e interrogar la complejidad del entorno en un escenario en el que tienen cabida

\footnotetext{
${ }^{3}$ Knowledge production depends on the transdisciplinary, on identifying larger patterns, and on hermeneutics as much as it does on facts, hypotheses and reproducible results. This means moving speculative and inventive inquiry from the margins to the center of what is deemed significant work.
}

ACE, 16 (4.6) CC BY-ND 3.0 ES | UPC Barcelona, España | Aporías de la investigación en arquitectura: adaptación del

modelo científico en la producción y divulgación del conocimiento explícito. DOI

http://dx.doi.org/10.5821/ace.16.46.9531 
aproximaciones cuantitativas, cualitativas y simbólicas, es una condición que ninguna disciplina independiente tiene. La arquitectura goza de una posición estratégica para la construcción de conocimiento dado que puede actuar desde múltiples enfoques. Además de la creación de objetos o experiencias, tiene la posibilidad de superar el acto técnico y aportar al pensamiento de la sociedad. Para Williams Robinson (2001) redefinir la arquitectura como un asunto cultural que incumbe a todos y como una disciplina que incorpora no solo la forma arquitectónica sino también sus efectos físicos y socioculturales, logra que los mundos de la academia y la práctica pueden volverse complementarios, haciendo de la arquitectura la poderosa fuerza política que debería ser.

\section{Comprender y adaptarse al modelo}

Para resolver las preguntas planteadas como objetivo de este artículo sobre la posibilidad de confrontar el pensamiento arquitectónico producido bajo la política editorial de siglo XX con el modo actual de divulgación académica, se propone un ejercicio analítico en el que la forma y los contenidos de teorías paradigmáticas se examinan bajo los criterios de producción científica. Los dos casos escogidos son el del equipo formado por el matrimonio Venturi-Scott Brown y el de Le Corbusier. Ambos representan apuestas teóricas que con marcos interpretativos diferentes buscaron dar respuesta a su tiempo e influyeron ampliamente en la teoría y práctica arquitectónica.

\subsection{Etnografía y sistematización de experiencias en Venturi y Scott Brown}

Entre los años sesenta y setenta Robert Venturi y Denise Scott Brown se convirtieron en agentes dinamizadores de un pensamiento arquitectónico que redundaba obstinadamente sobre el movimiento moderno. Buscaron demostrar que la realidad de su época no era aprehensible con esa lógica y que aquella retórica revolucionaria ya no funcionaba. Su tesis fue desarrollada desde la teoría, la práctica y la pedagogía. Venturi y Scott Brown, junto a Steven Izenour, tipificaron una experiencia educativa cuando visitaron Las Vegas con sus alumnos de Yale en otoño de 1968. Como resultado de este proceso, nacido en el salón de clase, produjeron un significativo análisis arquitectónico, cultural y urbano que involucraba temas de comunicación, cultura popular y estética. Aprendiendo de las Vegas (Venturi, Izenour y Scott Brown, 1998) de 1972, se convirtió en un texto clave para reforzar su concepción de la arquitectura desde el significado social y complementó las tesis desplegadas en su libro de 1966 Complejidad y contradicción en la arquitectura (Venturi, 1978).

Las conclusiones de la teoría de Venturi y Scott Brown son conocidas en el mundo de la arquitectura, pero en esta ocasión se trata de analizar la forma en que las ideas de estos arquitectos se fueron desarrollando y comunicando. El trabajo sobre Las Vegas parte de una indagación académica dividida en fases y que se autodefine como "investigación aplicada". El libro, que analiza la calle principal (strip), se organiza en dos partes y el capítulo inicial se plantea como un texto escrito según los resultados del trabajo de campo. El primer detalle importante aparece en el prólogo: "La finalidad de este estudio es llegar a comprender esa forma con la mente abierta, a través de una investigación desprovista de juicios de valor, y comenzar a desarrollar técnicas nuevas para su tratamiento" (Venturi, et al, 1998, pág. 12). La introducción continúa exponiendo unos objetivos definidos y añade una "preocupación pedagógica por transformar el tradicional «estudio» de arquitectura en una nueva herramienta para enseñar arquitectura, y nuestro particular interés en hallar medios gráficos más adecuados que los que hoy utilizan arquitectos y urbanistas para describir el urbanismo de «ramificación» y especialmente la vía comercial” (Venturi, et al, 1998, pág. 12).

El trabajo entonces se inscribe explícitamente como investigación y hace una declaración de intenciones de corte científico al evitar los juicios de valor. Proponen basarse en evidencia empírica,

ACE, 16 (4.6) CC BY-ND 3.0 ES | UPC Barcelona, España | Aporías de la investigación en arquitectura: adaptación del

modelo científico en la producción y divulgación del conocimiento explícito. DOI http://dx.doi.org/10.5821/ace.16.46.9531 
en la realidad exterior y no en las abstracciones estéticas comunes al pensamiento arquitectónico condenadas ya en el libro anterior. En el prólogo a la primera edición hacen una distinción: “Tampoco va dirigida nuestra critica a aquellos arquitectos y estudiosos que están desarrollando nuevas aproximaciones a la arquitectura en investigaciones a campos afines y métodos científicos". Además, estimulan la pluralidad de miradas: "En nuestra opinión, cuantas más direcciones tome la arquitectura en este punto, mucho mejor. La nuestra no excluye las suyas ni al contrario” (Venturi et al, 1998, pág. 14).

El trabajo de campo parte de una figura conocida en la pedagogía: "el viaje de arquitectura". Lo innovador reside en que la visita no buscó estudiar ciudades históricas o edificios icónicos sino analizar la organización urbana y el simbolismo de una ciudad en medio del desierto en la que casinos y hoteles son su principal arquitectura. En esta ocasión los usuales bocetos del Partenón, o los croquis de un foro romano, son reemplazados por el detallado análisis gráfico en el que fotografías, diagramas y planos se combinan con una categorización iconográfica que se dispone como la presentación de resultados.

La segunda parte del libro realiza una inmersión teórica en la que propone sus ya célebres categorías "pato" (duck) y "tinglado decorado" (decorated shield) para explicar el funcionamiento de la arquitectura como artefacto formal y comunicativo desde dos polos. Para hacer más gráfica la teoría se realiza una comparación entre la Guild House del propio Venturi (con John Rauch y Denise Scott Brown), y los apartamentos Crawford Manor de Paul Rudolph en un ejercicio no exento de provocación. Aunque hay un marco similar entre los capítulos del libro, no se establecen discusiones suficientemente estructuradas entre las partes que, de todos modos, funcionan bien de manera autónoma.

Para evaluar el impacto del libro en la comunidad científica se han recogido algunas reseñas publicadas en journals en lugar de las revistas tradicionales de arquitectura. Varias de ellas coinciden en la novedad del enfoque por su minuciosidad, ingenio y perspicacia (Beardsley, 1974) y por su intento admirable de crear un sistema simbólico para comunicarse fácilmente con el lector (Unruh, 1979). El libro es calificado de rareza por su habilidad y creatividad para utilizar la historia con conocimiento (Wolf, 1973). Las reseñas también permiten valorar la capacidad del texto para ofrecer una interlocución disciplinar amplia más allá de la arquitectura. Por ejemplo, con motivo del lanzamiento de la segunda edición el sociólogo David R. Unruh (1979) revisa el libro para el Journal of Contemporary Ethnography y subraya que ofrece una mirada novedosa de una ciudad que ha sido estudiada por los sociólogos, pero desde un enfoque diferente. Desde el campo de la historia, Gary Wolf (1973), escribe en el Journal of the Society of Architectural Historians que para un historiador el libro es un documento brillante y una revisión del patrimonio arquitectónico desde un punto de vista teórico. Por su parte, en The Journal of Aesthetics and Art Criticism, Beardsley (1974), exalta las reflexiones críticas sobre la arquitectura moderna, sobre los encargos en el arte y la iconología de las casas suburbanas. Estamos pues ante un texto de lecturas amplias y diferente al que el establecimiento de la arquitectura acostumbraba difundir. Establece intersecciones con otras disciplinas que pueden leerlo en clave sociológica, histórica, estética y crítica, pero que además es accesible como un trabajo de investigación con elementos comunes a sus disciplinas. Representa también un entendimiento de la arquitectura como hecho cultural dependiente y, como afirma Wolf (1973), amplía los fundamentos de la arquitectura y la sitúa como una herramienta poderosa para ser utilizada modestamente. Simboliza una vía contraria a la cerrada estética moderna, reconoce la heterogeneidad del entorno y se esfuerza por alcanzar un significado en todos los niveles de diversidad. La evidencia de lo "inclusivo" es una constante en el texto (Wolf, 1973). Otra de las virtudes, para Unruh (1973), es la audacia de los autores para entregar al lector una mezcla entusiasta y erudita de conjeturas, impresiones personales y crítica mordaz, pero a la vez detecta una desarticulación de las partes acompañada de hipótesis rudimentarias.

ACE, 16 (4.6) CC BY-ND 3.0 ES | UPC Barcelona, España | Aporías de la investigación en arquitectura: adaptación del

modelo científico en la producción y divulgación del conocimiento explícito. DOI: http://dx.doi.org/10.5821/ace.16.46.9531 
Revisando con minuciosidad el texto, no toda su estructura es comparable con el rigor científico. Hay fallos en las conclusiones que caen en un tono prescriptivo más cercano a la opinión que a tesis argumentadas desde los datos recogidos. Uno de los principales desaciertos es asumir un conocimiento sobre el gusto de las masas o la forma como los habitantes dan significado a aquella arquitectura cuando el trabajo de campo no los consulta. Si bien el trabajo tiene una perspectiva muy diferente a los análisis de forma y espacio, en el aspecto del gusto la observación cae en el tópico de la reflexión arquitectónica que ignora a los individuos. Es el ojo del arquitecto quien decide e interpreta el sentir de los demás. Unruh (1973) se pregunta con agudeza si a los residentes de los suburbios realmente les gusta ese tipo de arquitectura o si simplemente están limitados por lo que pueden pagar. Termina con mordacidad cuestionando: “¿Debemos suponer que un arquitecto de Nueva Jersey que estudia simbolismo arquitectónico sabe más sobre cómo se sienten la mayoría de las personas que esas mismas personas?”“ (pág. 123). Esta cuestión no queda clara en la investigación.

A pesar de estos detalles, la investigación de Venturi, Scott Brown e Izenour configura una suerte de etnografía experimental que se corresponde con metodologías ya asumidas por ciertos sectores de la sociología y la antropología en los que lo visual y lo gráfico juega un papel fundamental en la recolección de datos y presentación de resultados. Retomando el aspecto educativo antes mencionado, el trabajo con los estudiantes de Yale es un espacio potencial para una forma de investigación llamada "sistematización de experiencias", una categoría que sirve para divulgar el conocimiento surgido de prácticas pedagógicas. A partir de experiencias educativas se pueden hacer interpretaciones críticas de los elementos que han intervenido en el proceso haciendo explícita su lógica. Es una forma válida de producción de conocimiento muy útil para la comunidad educativa. De igual manera expande, profundiza y estructura la figura del "viaje de arquitectura" planteando un objetivo específico en contraposición a ejercicios contemplativos que se definen como una experiencia individual en la que la vivencia del espacio y los apuntes gráficos de cada estudiante establecen algún tipo de conocimiento tácito que cada cual sintetiza y apropia.

\subsection{Multi, trans e interdisciplinar: La investigación-creación en Le Corbusier}

La figura más paradigmática de la arquitectura moderna, Le Corbusier, sirve al objetivo de este análisis gracias a que desarrolló una amplia obra, teórica y construida, con gran difusión e influencia. Con independencia de las diferentes y hasta contradictorias posturas que el suizo defendió durante su carrera, el siguiente ejercicio no pretende hacer una revisión crítica de las mismas sino reordenar algunos planteamientos pues la estrecha relación entre pensamiento y práctica en Le Corbusier admite un análisis a la luz de procesos de investigación y creación como síntesis multidisciplinares. Su producción profesional desempeñó un papel fundamental en propuestas teóricas que hacen evidentes modos en que la práctica contribuye a la investigación y, como exigen Rust, Mottram y Till (2007), se distingue de otras formas de práctica por esa comprensión explícita de la condición investigativa.

Le Corbusier mantuvo una continua actitud de indagación y argumentación respaldada en la racionalidad moderna. El aporte del arquitecto a la disciplina (y en su caso también a la profesión, usando las categorías de Anderson, 2001) se llevó a cabo justo al expandir el campo disciplinar y, como afirma Wortham (2007), moviéndose "de los márgenes al centro" y nutriendo su quehacer y reflexión de otros problemas. Gran parte de los postulados y obras de su primera etapa se entienden como síntesis de indagaciones e influencias que fueron ampliamente argumentadas en su obra teórica. Prototipos como la Casa Dom-ino y diseños construidos como la Ville Savoye relacionan

\footnotetext{
${ }^{4}$ Are we to assume that a New Jersey architect studying architectural symbolism knows more about how most people feel than those people do?
}

ACE, 16 (4.6) CC BY-ND 3.0 ES | UPC Barcelona, España | Aporías de la investigación en arquitectura: adaptación del

modelo científico en la producción y divulgación del conocimiento explícito. DOI

http://dx.doi.org/10.5821/ace.16.46.9531 
pensamiento y práctica. La incorporación de temas externos, "no arquitectónicos" es clave en la conformación programática que dará vida a una nueva forma de entender la vivienda.

Si bien la conclusión más publicitada de esta primera época, les cinq points de l'architecture moderne, se ha reducido a un problema de forma y espacio, hay detrás un aparato teórico más complejo y amplio tal como se expone a continuación: la racionalización de recursos y tiempo que condujo a la modulación de materiales surge de la industrialización, es teóricamente formulada por el economista Frederick Taylor y puesta en práctica por Henry Ford a quienes el propio Le Corbusier cita como ejemplos a seguir en un congreso del CIAM (Mumford, 2000). Las nuevas técnicas constructivas son desarrolladas por ingenieros, de quienes el arquitecto suizo pide aprender. Este entendimiento se ve reflejado en el diseño y la producción de los trasatlánticos, automóviles y aviones (no en edificios), tan estudiados y referenciados por Le Corbusier (1998).

La ruptura de la axialidad clásica y del punto de vista único, que propicia una redefinición del espacio, viene de vanguardias como el cubismo (Giedion, 1959; Ozenfant y Jeanneret, 1993). El cuestionamiento estético y la reformulación de lo bello en la modernidad proviene de meditaciones filosóficas y sociales que abren el debate sobre el sentido del ornamento en la era industrial (Baudelaire, 1995; Loos, 1980). Las grandes ventanas, terrazas, superficies blancas y la búsqueda de asoleamiento, vienen de la recomendación para tratar la tuberculosis a principios del siglo XX (Colomina, 2019). Y la búsqueda de una dinámica secuencial en el recorrido, que fragmenta la experiencia del edificio, es decir, la promenade architecturale, tiene equivalencia con las teorías del montaje cinematográfico del que Le Corbusier reconoce, funciona de manera análoga a su arquitectura (Cohen, 1992 y Abel, 1993) y se conecta con la física y los estudios de la psicología de la percepción tan en boga en aquellos momentos.

Las anteriores influencias externas podrían ser producto de la intuición y situarse del lado del conocimiento tácito y, por tanto, salir del interés de este artículo. Sin embargo, fueron ampliamente documentadas y argumentadas por el arquitecto en una demostración del trasfondo intelectual que respaldaba su obra. Esta expansión de lo disciplinar fue fundamental para establecer un rumbo diferente en la concepción de la arquitectura y en la manera de proyectar. Para Le Corbusier el edificio no era solo respuesta a unas necesidades inmediatas del programa sino, un gran proyecto que debía recoger el signo de su tiempo.

Con el fin de ilustrar la posibilidad de organizar de manera explícita la simbiosis teórico-creativa, retomaremos de la enumeración anterior la promenade architecturale (traducida como el paseo arquitectónico), un concepto que puede mostrar la relación entre disciplina y profesión o, en otras palabras, entre investigación y creación. Le Corbusier contribuyó a la definición de modernidad como percepción dinámica, una idea que influyó a los artistas comenzando el siglo XX. Justifica sus tesis con diversos argumentos, uno de ellos es histórico y cultural, basado en su viaje a Oriente. Para descalificar la pertinencia de la arquitectura barroca acude a la ciudad árabe que, según Le Corbusier, "es cinemática, [...] se aprecia en marcha, a pie; es caminando, desplazándose como se va viendo el desarrollo de las ordenaciones de la arquitectura. Éste es un principio contrario a la arquitectura barroca que es concebida sobre el papel, alrededor de un punto fijo teórico. Yo prefiero la enseñanza de la arquitectura árabe" (Boesiger, 1935, pág. 24). ${ }^{5}$

En sus documentadas conversaciones con estudiantes remarca que la arquitectura es para recorrer. No debe ser entendida como una limitada ilusión gráfica organizada para un hombre situado en el

${ }^{5}$ L'architecture arabe nous donne un enseignement précieux. Elle s'apprécie a la marche, avec le pied; -c'est en marchan/,
en se déplacant que l'on voit se développer les ordonnances de l'architecture. C'est un príncipe contraire á /'architecture
baroque qui est concue sur Je papier, autour d'un point fixe théorique. Je préfere l'enseignement de l'architecture árabe.

ACE, 16 (4.6) CC BY-ND 3.0 ES | UPC Barcelona, España | Aporías de la investigación en arquitectura: adaptación del

modelo científico en la producción y divulgación del conocimiento explícito. DOI:

http://dx.doi.org/10.5821/ace.16.46.9531 
centro ya que tiene una completa visión simultánea, circular y periférica ("ojo de mosca", textualmente): "nuestro hombre camina se desplaza, se ocupa de sus quehaceres, registrando así el desarrollo de los hechos arquitectónicos aparecidos uno a continuación del otro" (Le Corbusier, 2001, pág. 32). La idea de "registro" es sin duda muy cinematográfica.

Las reflexiones sobre el recorrido están asociadas a la nueva apreciación del espacio-tiempo que el cubismo y el cine ofrecieron a principios del siglo XX. Le Corbusier hace mención directa a ello cuando analiza la representación cinematográfica, señala su carácter ilusorio y detecta la eficacia del montaje: "Simplemente explota una notable ventaja técnica: la eliminación de las transiciones, la posibilidad fácil de suprimir los «espacios muertos». Por lo tanto, nos alivia con imágenes, a veces atractivas. Y esperamos pacientemente, esperamos." (Abel, 1993, pág. 111). Este texto del arquitecto, publicado en la revista Mouvement I de 1933, se titula "Esprit de vérité" y refleja la búsqueda de lo esencial en las artes, un proceso que habían comenzado las vanguardias hacía un par de décadas. Es bajo este criterio que Le Corbusier ataca el teatro, un arte que se dedica a contar historias con grandilocuencia interponiéndose, según el suizo, "entre nosotros y el verdadero voyeur: la lente” (Abel, 1993, pág. 111).

La referencia que hacía Le Corbusier al teatro y "la lente" demuestra gran resonancia con los manifiestos soviéticos del cine. Le Corbusier viajó a Moscú en 1928 y según Cohen, (1992) mostró un gran interés en filmes de la vanguardia soviéticos. Será el mismo Sergei Eisenstein, padre de la teoría del montaje, quien lo reciba en el Museo Politécnico de Moscú donde el arquitecto dio una charla. Le Corbusier erige al cine y la arquitectura como las dos únicas artes de su tiempo y se compara con Eisenstein argumentando que sus películas se parecen a lo que el arquitecto está tratando de hacer, es decir, elevando "los acontecimientos cotidianos que escapan de nuestra atención superficial al nivel de imágenes monumentales" (Cohen, 1992, pág. 49). Estamos ante una retroalimentación teórica entre el montaje y la promenade.

La exploración de Le Corbusier sobre lo secuencial, se ve también plasmada en su libro de 1923 Hacia una arquitectura (1998). Si bien en 1911 había quedado deslumbrado por la Acrópolis de Atenas en su peregrinaje por Oriente, y lo habría descrito con lenguaje poético, será una década después que lo racionalice. En su análisis resalta el orden que rompe la unicidad axial: "no hay que poner todas las cosas de la arquitectura sobre ejes, pues serían como otras tantas personas hablando a la vez" (Le Corbusier, 1998, pág. 151) y valora los múltiples fragmentos perceptivos que el recorrido propone entre el paisaje y la arquitectura. Para su explicación usa las plantas y dibujos axonométricos de Choisy, copiados de la Histoire de l'architecture de 1899. El pasaje de Choisy sobre la Acrópolis ciertamente se organiza desde una secuencialidad, el historiador numera en la planta los monumentos para organizar su narrativa de modo que el recorrido se estructura como un guion cinematográfico según el orden que Choisy desvela.

La síntesis de todas estas elucubraciones teóricas se plasma en varios diseños que funcionaban como comprobación de conceptos sobre la nueva espacialidad de la arquitectura. Estas experimentaciones comienzan en 1923 con la Ville La Roche y culminan en 1931 con la construcción de la Ville Savoye. Para describir la Ville La Roche, Le Corbusier anota: "Por lo tanto, esta segunda casa se sentirá un poco como un paseo arquitectónico. Entramos: el espectáculo arquitectónico se ofrece de inmediato a la vista: seguimos un itinerario y las perspectivas se desarrollan con gran variedad; jugamos con la entrada de luz que ilumina las paredes o crea oscuridad. Los vanos se abren al exterior donde encontramos la unidad arquitectónica”6 (Boesiger y Stonorov, 1967, pág, 60).

\footnotetext{
${ }^{6}$ Cette seconde maison senra done un peu comme une promenade architecturale. On entre: le espectacle architectural s'offre de suite au regard: on suit un itinéraire et les perspectives se développent avec une grande variété; on joue avec l'afflux de la lumière éclairant les murs ou créant des pénombres.
}

ACE, 16 (4.6) CC BY-ND 3.0 ES | UPC Barcelona, España | Aporías de la investigación en arquitectura: adaptación del modelo científico en la producción y divulgación del conocimiento explícito. DOI: http://dx.doi.org/10.5821/ace.16.46.9531 
El carácter fenomenológico se enfatiza con el diseño. La rampa de ascenso, el puente que comunica dos zonas, el balcón con visión hacia el primer piso y las ventanas dispuestas estratégicamente para la observación plasman una idea.

Con un lenguaje acorde a la naturaleza dinámica de la promenade, la Villa Savoye es explicada en un filme de Pierre Chenal, que con la colaboración de Le Corbusier, presentó en 1931 tres documentales: Batir, L'architecture d'Aujourd'hui y Chantiers trois. En la secuencia dedicada a la Ville Savoye, una actriz ejerce de guía recorriendo la casa. La cámara va repasando sistemáticamente los cinco puntos de la arquitectura, la lente registra en horizontal el gran ventanal, luego baja al suelo remarcando la verticalidad de una columna y acceder al interior. Los movimientos de la protagonista, seguida por la cámara, enfatizan las cualidades cinemáticas de la casa con su promenade.

Desde el viaje a Oriente hasta la culminación de la Ville Savoye Le Corbusier logra dar sentido a la propia experiencia, a los dibujos y a la descripción de Choisy, a la fragmentación del espacio tiempo del cubismo y a la teoría del montaje cinematográfico. Si bien Benton (1987) argumenta que la promenade surge de manera fortuita en el proceso de diseño, cabe anotar que la serendipia (si fuera el caso), es decir, el hallazgo producido de manera casual puede construir conocimiento gracias a la capacidad del analista para prestar atención a los detalles. El hallazgo accidental estimula al investigador a profundizar en el suceso y definirlo hasta llegar a la certeza de haber comprendido el fenómeno, tal cual nos muestra Le Corbusier.

Por supuesto, la cientificidad de algunas conjeturas es cuestionable. Muchas de sus ideas no están exentas de juicios de valor, una estrategia por demás común de las vanguardias. Llega a afirmar que lo viva o muerta de una arquitectura se mide "según si la regla de recorrido haya sido observada o no, o que al contrario ella sea explotada brillantemente" (Le Corbusier, 2001, pág. 32). Y complementa: "La buena arquitectura 'se camina' y se 'recorre' tanto adentro como afuera. Es la arquitectura viva. La mala arquitectura está coagulada alrededor de un punto fijo, irreal, ficticio, extraño a la ley humana" (Le Corbusier, 2001, pág. 33). Es también evidente la falta de rigor, pues omite dar crédito a Choisy de quien toma ideas y dibujos para su libro. Con todo, hay una búsqueda teórica que se investiga desde el edificio y que ofrece una gran cantidad de ideas formuladas y construidas susceptibles de ser sintetizadas de forma explícita para evaluación y escrutinio de sus pares, tal cual se expone a continuación.

\subsection{Un "paper" de Le Corbusier}

Reseñar textos nunca escritos ha sido una práctica literaria en la que Borges y Lem fueron maestros. En este caso es una herramienta para exponer de forma explícita los argumentos de este artículo y responder las preguntas inicialmente planteadas. Al hilo de lo anterior, se considera que la obra de Le Corbusier es un ejemplo idóneo para expresar la adecuación entre teoría y práctica. Sin haber pertenecido al ámbito académico sus planteamientos son susceptibles de formalizar y ordenar bajo el modelo de escritura científica.

Para este caso, las ideas sobre el dinamismo, como concepto articulador de la experiencia espacial, fueron expresadas de manera analítica en textos y tuvieron un desarrollo práctico. Entendiendo que el cierre de un proceso de investigación-creación no es la obra, sino el conocimiento explícito que surge de la experiencia creativa, se formula acá el resumen (abstract) de un hipotético artículo de 1932 escrito por el suizo y que reza así:

ACE, 16 (4.6) CC BY-ND 3.0 ES | UPC Barcelona, España | Aporías de la investigación en arquitectura: adaptación del modelo científico en la producción y divulgación del conocimiento explícito. DOI: http://dx.doi.org/10.5821/ace.16.46.9531 


\title{
La arquitectura como generadora de la experiencia espacial dinámica: hacia una redefinición del hábitat doméstico
}

\author{
Charles Edouard Jeanneret ${ }^{7}$
}

35 rue de Sèvres, 75006. París

\section{Resumen}

Tomando como punto de partida los nuevos medios técnicos y materiales propiciados por la industrialización y la redefinición estética que del espacio hicieron el cubismo y el montaje cinematográfico, este artículo presenta una propuesta teórica que se valida en dos casos de estudio. Las nuevas condiciones espaciotemporales establecidas por la mecanización hacen necesario revisar los modos en que la vivienda ha sido concebida. Esto implica una exploración de la forma moderna de habitar acorde con las nuevas circunstancias en las que el dinamismo irrumpe como ruptura a la concepción espacial estática heredada del Barroco. El artículo toma como base el propio trabajo profesional realizado durante la pasada década para presentar de manera sistemática las soluciones espaciales desarrolladas desde el dinamismo secuencial del recorrido. A manera de conclusión propone un modelo de cinco puntos como síntesis proyectual que permite articular todas las condiciones antes mencionadas y ofrece la posibilidad de replicarse en diferentes ámbitos. Por último, presenta la implementación del modelo a través del caso de dos viviendas unifamiliares construidas en las inmediaciones de París (La Ville La Roche, 1923 y La Ville Savoye, 1929) en las que el recorrido configura la experiencia del espacio doméstico.

Palabras clave: espacio arquitectónico; los cinco puntos de la arquitectura; modernidad; promenade architecturale.

\section{Peroratio}

El conocimiento tácito, no se comunica sistemáticamente desde el lenguaje verbal y en el caso de la arquitectura se encarna en la poiesis, pero comporta conocimientos posibles de comunicar sistemáticamente, no solo referidos a la tekné sino también a la arquitectura como hecho cultural. Una investigación que pueda expresar conocimiento explícito requiere de espacios flexibles que admitan puntos de vista híbridos situados entre las líneas consolidadas del análisis arquitectónico dirigido a la teoría o a la práctica. La condición colectiva de la arquitectura y de participación social implica una producción amplia de conocimiento, pues su razón de ser es el ser humano en sus diferentes dimensiones y no un compromiso disciplinar exclusivo.

La ciudad, como entidad sujeta a fuerzas externas que superan el control interno de cualquier profesión, es un ámbito inconmensurable que pide constantemente nuevas formas de interpretación. Asumir la arquitectura de un modo inmutable, autorreferencial e independiente, excluye lo dinámico y cambiante, lo vivo. Siguiendo a Till (2009), los arquitectos tienden a negar la dependencia de su campo, se sienten más cómodos en un mundo de ciertas predicciones, con un método lineal, en la búsqueda de perfección. Entonces, aceptar la dependencia no debe ser visto como una amenaza disciplinar sino como una oportunidad.

La difusión de resultados es una etapa fundamental en la investigación y, a su vez, la parte más débil en la cadena del conocimiento arquitectónico. No hacer explícitos los hallazgos redunda en repeticiones innecesarias y en que se trunque la cualidad incremental y acumulativa que lleva a la innovación. En referencia a los medios de difusión, la transmisión del conocimiento es un hecho social

\footnotetext{
${ }^{7}$ Arquitecto. Miembro fundador del Congrès International d'Architecture Moderne
}

ACE, 16 (4.6) CC BY-ND 3.0 ES | UPC Barcelona, España | Aporías de la investigación en arquitectura: adaptación del modelo científico en la producción y divulgación del conocimiento explícito. DOI: http://dx.doi.org/10.5821/ace.16.46.9531 
y por tanto se adapta a modelos regidos por protocolos que se validan con el tiempo por la comunidad. Existe una "selección natural" en los modos de comunicar que se va decantando, como demuestra el auge de las revistas científicas. Obras paradigmáticas como las de Le Corbusier y Venturi con Scott Brown generaron ideas en marcos que, con más sistematicidad, podrían entrar en la actual retórica que la comunidad científica establece como producción válida de conocimiento. Ellos lo intentaron buscando un pensamiento crítico con formas apropiadas para exponer ideas de modo ordenado y convincente. Venturi y Scott Brown amalgamaron metodologías etnográficas con recopilación de datos por medio de diagramas e imágenes; incorporaron sin prejuicios un entendimiento del espacio y la arquitectura con un enfoque incluyente que trascendió a la disciplina y aportó conocimiento a problemáticas culturales globales. Le Corbusier usó su misma obra como dispositivo para la exploración de postulados teóricos, hizo una síntesis de diversos conocimientos en una época de cambios. Su obra permite delimitar problemáticas a las que el arquitecto ha llegado desde la reflexión de su trabajo. Se planteó objetivos susceptibles de formular y volvió su práctica una metodología que puede hacerse explícita. La difusión de sus ideas propició algo clave para la producción de conocimiento y es que las mismas pudieran ser evaluadas, criticadas y refutadas desde fundamentos epistemológicos, incluso para señalar sus contradicciones. Le Corbusier y Venturi-Scott Brown dotaron sus obras de un conocimiento denso fruto de teorizaciones paralelas en las que el edificio se convertía en comprobación de las conjeturas. En ese sentido, permiten pensar en un vínculo natural de la investigación con la práctica y la educación. El modelo australiano es un ejemplo de esta articulación en niveles superiores que está siendo seguido en otros países, sin embargo, es también importante pensar la investigación desde el pregrado sin sacrificar el ejercicio profesionalizante para estimular una cultura de pensamiento. Gran parte del conocimiento que se produce en proyectos arquitectónicos de fin de grado queda implícito en la documentación final (memoria, planos y modelos), es decir, un conocimiento tácito que ni siquiera se concreta como objeto verificable desde la experiencia edificada. Su conocimiento queda integrado en los medios de representación gráficos cuyo nivel de divulgación es técnico, sujeto a una decodificación que tiende a describir el dispositivo tecnológico llamado edificio. Esta instancia, que comporta un juicioso estudio y documentación previa al diseño, tiene la potencialidad de dar un paso más y convertirse en una investigación cuyos resultados explícitos, a la luz de su verbalización, se pueden divulgar y compartir cerrando el círculo de la investigación-creación para revelar el modo en que la práctica contribuye a la investigación.

El conocimiento arquitectónico entonces debe y puede plantearse de una forma verificable, abierta a la crítica razonada y, además, alinearse con el rigor de la investigación en otros campos para desarrollarse en sus propios términos. Tiene a favor su condición híbrida que le permite abordar el problema investigativo desde un amplio espectro en el que toma prestados métodos, sin perder la experticia del arquitecto en compositio, es decir, su capacidad para integrar, intersecar, articular y disponer de forma ordenada y constructiva tantos sistemas simultáneos en el espacio. Tal cualidad es susceptible de mantener en el campo teórico y su carácter relacional puede aportar a otras formas de investigación tradicionales que buscan sus resultados desde razonamientos lineales.

\section{Agradecimientos}

Este artículo ha sido desarrollado dentro del programa de investigación Nuevo doctor de la Pontificia Universidad Javeriana de Cali. El autor agradece a la profesora Sabina Cárdenas O'Byrne por la cuidadosa lectura y sus certeras observaciones.

Conflicto de intereses: Los autores declaran que no hay conflicto de intereses.

ACE, 16 (4.6) CC BY-ND 3.0 ES | UPC Barcelona, España | Aporías de la investigación en arquitectura: adaptación del modelo científico en la producción y divulgación del conocimiento explícito. DOI: http://dx.doi.org/10.5821/ace.16.46.9531 


\section{Bibliografía}

Abel, R. (1993). French film theory and criticism: A history / anthology; 1907-1939. Princeton: University Press.

Alcolea, R. (2012). La construcción de un mito Richard J. Neutra en Europa. En, Las revistas de arquitectura (1900-1975): Crónicas, manifiestos, propaganda: actas preliminares (pp. 23-34). Pamplona, España: T6) Ediciones SL.

Anderson, S. (2001). The Profession and Discipline of Architecture: Practice and Education. En A. Piotrowski y J. Williams Robinson (Eds.). The Discipline of Architecture (pp. 61-82). Minneapolis, EEUU: University of Minnesota Press.

Baudelaire, Ch. (1995). El pintor de la vida moderna. Valencia, España: Colegio oficial de aparejadores y arquitectos técnicos.

Beardsley, M. (1974). [Reseña del libro Learning from Las Vegas, por R. Venturi, D. Scott Brown y S. Izenour]. The Journal of Aesthetics and Art Criticism, 33(2), 245-246.

Benton, T. (1987). Le Corbusier y la promenade architecturale. Revista de Arquitectura y Urbanismo del Colegio Oficial de Arquitectos de Madrid, 264-265, 38-47. Recuperado de http://www.coam.es/media/Default\%20Files/fundacion/biblioteca/revista-arquitectura-100/19871990/docs/revista-articulos/revista-arquitectura-1987-n264-265-pag38-47.pdf

Boesiger, W. (Ed.) (1935). Le Corbusier et Pierre Jeanneret. Oeuvre complete de 1929-1934. Zurich, Suiza: Les editions d'architecture.

Boesiger, W., y Stonorov, O. (1967). Oeuvre complete, 1910-1929. Zurich, Suiza: Les editions d'architecture.

Burry, M. (2017) Innovation in high-level capture and diffusion of tacit architectural knowledge. ACE: Architecture, City and Environment, 12(34), 291-300. DOI: http://dx.doi.org/10.5821/ace.12.34.5295

Chávez, J. (2015). La investigación en los campos de la arquitectura. Reflexiones metodológicas y procedimentales. Medellín, Colombia: Universidad Nacional de Colombia.

Cohen, J. (1992). Le Corbusier and the mystique of the USSR: Theories and projects for Moscow, 19281936. Princeton: Princeton University Press.

Colomina, B. (2012). Little Magazines: Small Utopia. En, Las revistas de arquitectura (1900-1975): Crónicas, manifiestos, propaganda: actas preliminares (pp. 13-22). Pamplona, España: T6) Ediciones SL.

Colomina, B. (2019). X-Ray Architecture. Zurich, Suiza: Lars Multer Publishers.

Creswell, J. \& Poth, Ch. (2018). Qualitative Inquiry and Research Design Choosing Among Five Approaches. Los Ángeles, EEUU: Sage.

ACE, 16 (4.6) CC BY-ND 3.0 ES | UPC Barcelona, España | Aporías de la investigación en arquitectura: adaptación del modelo científico en la producción y divulgación del conocimiento explícito. DOI: http://dx.doi.org/10.5821/ace.16.46.9531 
Fayos, F. (2017). El proyecto arquitectónico a la luz del "paradigma indicial". ACE: Architecture, City and Environment, 12 (34), 283-290. DOI: http://dx.doi.org/10.5821/ace.10.5821/ace.12.34.5294

Frayling, C. (1993-94). Research in Art and Design. Royal College of Art Research Papers, 1(1), 15. Recuperado de http://researchonline.rca.ac.uk/384/3/frayling research in art and design_1993.pdf

Furlong, J. \& Oancea, A. (2005). Assessing quality in applied and practice-based research in education: a framework for discussion. Oxford University Department of Educational Studies. Recuperado de https://www.birmingham.ac.uk/Documents/college-social-sciences/education/projects/esrc-2005seminarseries5.pdf

Gastón, C. y Rovira, T. (2007). El Proyecto moderno. Pautas de investigación. Barcelona, España: Edicions UPC.

Gehl, J. \& Svarre, B. (2013). How to study public life. Washington, Island Press.

Giedion, S. (1959). Space, Time and Architecture. The Growth of a New Tradition. Cambridge, EEUU: Harvard University Press.

Ginzburg, C. (1999). Mitos, emblemas e indicios. Morfología e historia. Barcelona, España: Editorial Gedisa, S.A.

Groat, L. \& Wang, D. (2013). Architectural Research Methods. Hoboken, John Wiley \& Sons, Inc.

Hillier, B. \& Leaman, A. (1976). Architecture as a discipline. Journal of Architectural Research, 5 (1), 2832. Recuperado de https://www.jstor.org/stable/43474204

Le Corbusier. (1998). Hacia una arquitectura. Barcelona, España: Ediciones Apóstrofe.

Loos, A. (1980). Ornamento y delito. Y otros escritos. Barcelona, España: Editorial Gustavo Gili, S.A.

Lucas, R. (2016). Research Methods for Architecture. London: Laurence King Publishing Ltd.

Mumford, E. (2000). The CIAM Discourse on Urbanism, 1928-1960. Cambridge, Mass: MIT Press.

Neutra, R. (1927). Wie baut Amerika? Stuttgart: J. Hoffmann.

Otxotorena, J. (2012). Arquitectura y revistas. Modernidad y publicística. En, Las revistas de arquitectura (1900-1975): crónicas, manifiestos, propaganda: actas preliminares (pp. 9-10). Pamplona, España: T6) Ediciones SL.

Ozenfant, A. y Jeanneret, Ch. (1993). Acerca del purismo. Escritos 1918-1926. Madrid, España: El Croquis Editorial.

Piotrowski, A. \& Williams Robinson, J. (2001). (Eds). The Discipline of Architecture. Minneapolis: University of Minnesota Press.

Rust, C., Mottram, J. y Till, J. (2007). Review of practice-led research in art, design \& architecture. UK, Arts and Humanities Research Council. Recuperado de http://shura.shu.ac.uk/7596/1/PacticeledReviewNov07.pdf

ACE, 16 (4.6) CC BY-ND 3.0 ES | UPC Barcelona, España | Aporías de la investigación en arquitectura: adaptación del 20 modelo científico en la producción y divulgación del conocimiento explícito. DOI: http://dx.doi.org/10.5821/ace.16.46.9531 
Samuel, F. (2017) Supporting Research in Practice, The Journal of Architecture, 22 (1), 4-10. DOI: http://dx.doi.org/10.1080/13602365.2017.1280288

Sullivan, G. (2006). Research Acts in Art Practice. Studies in Art Education, 48 (1), 19-35. DOI: https://doi.org/10.2307/25475803

Till, J. (2007). Architectural research: three myths and one model. Building Material, 17, 4-10. Recuperado de https://jeremytill.s3.amazonaws.com/uploads/post/attachment/34/2007 Three Myt $\underline{\text { hs and One Model.pdf }}$

Till, J. (2009). Architecture Depends. Cambridge: The MIT Press.

Torrent, H. (Comp.) (2013). Revistas, Arquitectura y Ciudad: representaciones en la cultura moderna. Pamplona, España: T6) Ediciones SL.

Unruh, D. (1979) [Reseña del libro Learning from Las Vegas, por R. Venturi, D. Scott Brown y S. Izenour]. Journal of Contemporary Ethnography, 8(1), 120-123.

Venturi, R, (1978). Complejidad y contradicción en la arquitectura. Barcelona, España: Editorial Gustavo Gili, S.A.

Venturi, R., Izenour, S. y Scott Brown, D. (1998). Aprendiendo de Las Vegas. El simbolismo olvidado de la forma arquitectónica. Barcelona, España: Editorial Gustavo Gili, S.A.

Williams Robinson, J. (2001). The Form and Structure of Architectural Knowledge: From Practice to Discipline. En A. Piotrowski y J. Williams Robinson (Eds.). The Discipline of Architecture (pp. 61-82). Minneapolis, EEUU: University of Minnesota Press.

Wolf, G. (1973). [Reseña del libro Learning from Las Vegas por R. Venturi, D. Scott Brown y S. Izenour]. Journal of the Society of Architectural Historians, 32(3), 258-260.

Wortham, B. D. (2007). The Way We Think about the Way We Think. Architecture is a Paradigm for Reconsidering Research. Journal of Architectural Education, 61 (1), 44-53. DOI: https://doi.org/10.1111/j.1531-314X.2007.00127.x

ACE, 16 (4.6) CC BY-ND 3.0 ES | UPC Barcelona, España | Aporías de la investigación en arquitectura: adaptación del modelo científico en la producción y divulgación del conocimiento explícito. DOI: http://dx.doi.org/10.5821/ace.16.46.9531 